\title{
Epoxidation and oxidation reactions using 1,4-butanediol dimethacrylate crosslinked polystyrene-supported tertiary butyl hydroperoxide
}

\author{
M S SHEELA $^{1}$ and K SREEKUMAR ${ }^{2}$ \\ ${ }^{1}$ Department of Chemistry, University of Kerala, Kariavattom Campus, Thiruvananthapuram 695 581, India \\ ${ }^{2}$ Department of Applied Chemistry, Cochin University of Science and Technology, Kochi 682 022, India \\ e-mail: ksk@cusat.ac.in
}

MS received 3 March 2004; revised 1 October 2004

\begin{abstract}
Butanediol dimethacrylate (1,4-BDDMA) crosslinked polystyrene-supported $t$-butyl hydroperoxide was employed in the epoxidation of olefins and oxidation of alcohols to carbonyl compounds. The reagent proved to be successful as a recyclable solid phase organic reagent with as much or more efficiency when compared to its monomeric counterpart. The extent of reaction was found to be dependent on various reaction parameters like solvent, temperature, molar concentration and presence of catalyst.
\end{abstract}

Keywords. Polystyrene-supported reagent; $t$-butyl hydroperoxide; solid-phase organic reagent; recyclability; epoxidation; oxidation.

\section{Introduction}

Solid-phase organic synthesis has been used as an efficient technique for the synthesis and screening of a large number of organic compounds. ${ }^{1}$ Over the past years, numerous techniques have been used to study polymeric resins commonly utilized in solid phase synthesis to allow greater understanding of the chemical nature and physical properties of the supports. In addition, to overcome some of the drawbacks of existing polymer supports, several new resins and new methods of handling solid supports have been developed. ${ }^{2-4}$ New methodologies have also been introduced to simplify the preparation of solid supports. A number of reactive species have been attached to polymeric supports and have been successfully used in organic synthesis. ${ }^{5-9}$ Polymerbound reagents have been reported for the oxidation of various alcohols. ${ }^{10}$ Peroxy compounds are widely used as initiators for polymerisation of monomers. However, they are not popular as solid-phase organic reagents. Divinyl benzene cross-linked polystyrenesupported $t$-butyl hydroperoxide has already been developed in our laboratory, as a recyclable solidphase organic reagent for performing various synthetic transformations. ${ }^{11}$ Reactivity of the attached functional group is strongly influenced by the nature

\footnotetext{
$\overline{\text { *For correspondence }}$
}

of the polymer backbone. ${ }^{12-15} 1,4-$ BDDMA crosslinked polystyrene-supported $t$-butyl hydroperoxide has also been developed for the conversion of alkyl and aryl halides to hydroxy compounds through a Grignard type reaction. ${ }^{16}$ In this article, we present the epoxidation of olefins and oxidation of alcohols using 1,4-BDDMA crosslinked polystyrene-supported $t$-butyl hydroperoxide.

\section{Experimental}

\subsection{General}

Solvents used were of reagent grade and were purified according to literature procedures. Melting points were determined on a hot stage melting point apparatus and are uncorrected. IR spectra were recorded on a Perkin-Elmer 887 IR spectrometer using $\mathrm{KBr}$ pellets. Thin layer chromatography (tlc) was performed on pre-coated silica gel plates.

\subsection{Epoxidation of olefins - General procedure}

The olefin $(1 \mathrm{mmol})$ in dioxan $(30 \mathrm{ml})$ was stirred with a two-fold molar excess of the polymer-supported $t$ butyl hydroperoxide reagent. ${ }^{16}$ The reaction was monitored by tlc as well as by estimating the residual hydroperoxide capacity. The epoxide content was determined by estimating the amount of oxirane 
oxygen by back titration with $1 \mathrm{~N} \mathrm{HCl}$ in the presence of dioxan. After completion of reactions, resin was filtered and washed with dioxan $(10 \mathrm{ml} \times 3$ times). The combined filtrate and washings, on evaporation of the solvent afforded the corresponding epoxides.

\subsection{Oxidation of alcohols - General procedure}

The alcohol ( $1 \mathrm{mmol})$, dissolved in chloroform $(20 \mathrm{ml})$, was stirred with a five-fold molar excess of the polymer-supported $t$-butyl hydroperoxide resin. The reaction was followed by tlc. After the completion of the reaction the resin was filtered and washed with chloroform. The combined filtrate and washings, on evaporation of the solvent afforded the corresponding carbonyl compounds.

\section{Results and discussion}

\subsection{Preparation and characterization of the reagent}

Two percent 1,4-BDDMA crosslinked polystyrene (1) was prepared by suspension polymerization. The white bead-shaped polymer obtained was purified by soxhlet extraction using tetrahydrofuran. It was identified by the characteristic IR spectral peaks at $1520 \mathrm{~cm}^{-1}$ (C=C str), $906 \mathrm{~cm}^{-1}$ (vinyl group, $\mathrm{C}-\mathrm{H}$ bending), $3030 \mathrm{~cm}^{-1}$ (C-H str) and $1740 \mathrm{~cm}^{-1}(\mathrm{C}=\mathrm{O}$ ester). The polystyrene resin was functionalized with $t$-butyl hydroperoxide group by a three-step polymer analogous reaction (scheme 1). The 2-oxopropyl polystyrene (2) was estimated by iodoform reaction to possess a $\mathrm{CH}_{3} \mathrm{COCH}_{2}-$ capacity of $4.2 \mathrm{meq} / \mathrm{g}$ of the polymer. Spectral characterization showed intense absorption band at $1720 \mathrm{~cm}^{-1}$ in the infrared region. When the 2-oxopropyl polystyrene resin was converted to polymeric $t$-butyl alcohol resin (3) the absorption observed for the keto resin at $1720 \mathrm{~cm}^{-1}$ disappeared indicating the conversion of the keto group. The polymeric $t$-alcohol was estimated to possess a capacity of $3.2 \mathrm{meq} / \mathrm{g}$ by the gravimetric method. Polymeric $t$-butyl alcohol was converted to $t$-butyl hydroperoxide reagent by the action of $\mathrm{H}_{2} \mathrm{O}_{2}$ in the cold, in the presence of $70 \%$ $\mathrm{H}_{2} \mathrm{SO}_{4}$. The resin exhibited strong absorption bands at $876 \mathrm{~cm}^{-1}, 1580 \mathrm{~cm}^{-1}$ (C=C arom str) and $3310 \mathrm{~cm}^{-1}$ $(\mathrm{O}-\mathrm{H}$ str) in the infrared region. The resin was estimated iodimetrically to possess a hydroperoxide capacity of $3.31 \mathrm{meq} / \mathrm{g}$. The 1,4-BDDMA crosslinked polystyrene backbone was found to be more reactive towards functionalization. Utilization of the crosslinker, 1,4-BDDMA, instead of DVB, raised the hydroperoxide capacity of the polymeric reagent from $2.86 \mathrm{meq} / \mathrm{g}$ to $3.31 \mathrm{meq} / \mathrm{g}$ when the reaction was performed under identical conditions. This may be attributed to the hydrophilic and flexible nature of the 1,4-BDDMA crosslinks imparting better hydrophobic-hydrophilic balance for the macromolecular environment.

\subsection{Epoxidation of olefins}

The 1,4-BDDMA crosslinked polystyrene bound reagent was found to epoxidise various olefins as shown in table 1. Epoxidation of olefins with the $t$ butyl hydroperoxide reagent is as shown in scheme 2 .
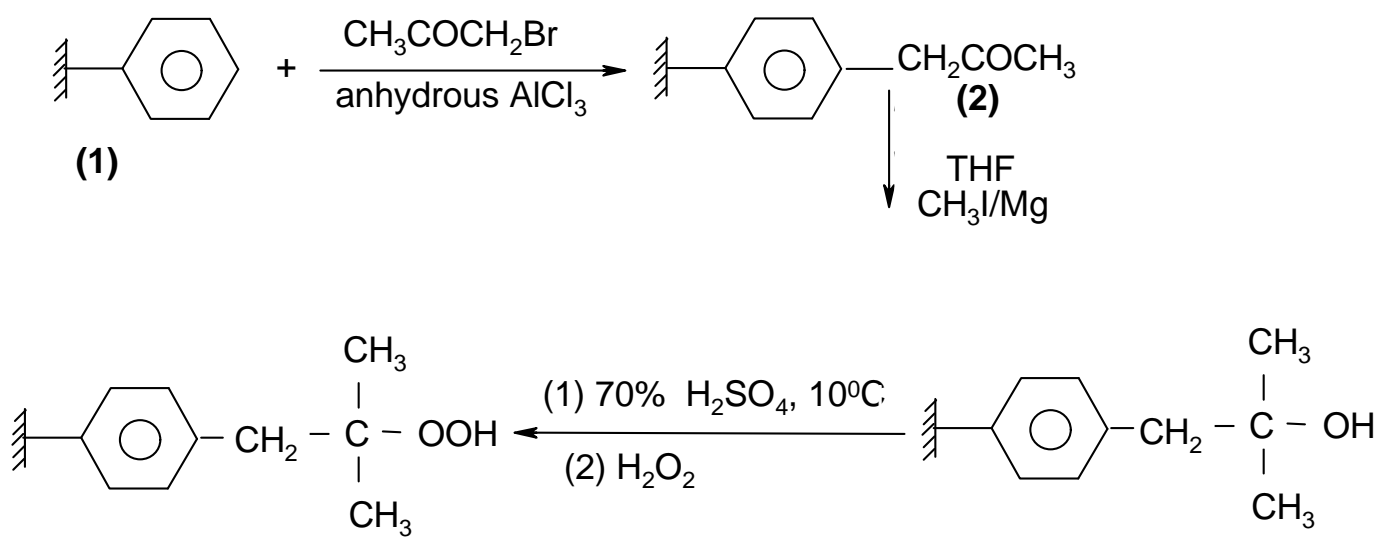

(4)

(3)

Scheme 1. Functionalisation of polystyrene resin. 
Table 1. Epoxidation of olefins using 1,4-BDDMA-crosslinked polystyrene supported $t$ butyl hydroperoxide.

\begin{tabular}{lclc}
\hline Olefin $^{\mathrm{a}}$ & $\begin{array}{c}\text { Reaction } \\
\operatorname{time}^{\mathrm{b}}(\mathrm{h})\end{array}$ & \multicolumn{1}{c}{ Product $^{\mathrm{c}}$} & $\begin{array}{c}\text { Isolated } \\
\text { yield (\%) }\end{array}$ \\
\hline Cinnamic acid & 39 & Phenyl glycidate & 40 \\
Ethyl cinnamate & 23 & Ethyl phenyl glycidate & 58 \\
Allyl bromide & 28 & Epibromohydrin & 52 \\
Styrene $^{\mathrm{d}}$ & 48 & Styrene oxide & 54 \\
Cyclohexene $^{\text {Methyl methacrylate }}{ }^{\mathrm{d}}$ & 16 & Cyclohexene oxide & 54 \\
Acenaphthylene $^{\mathrm{d}}$ & 21 & Epoxymethyl propionate & 50 \\
Diphenyl acetylene & 36 & Acenaphthylene oxide & 44 \\
2-Chloroacrylonitrile & 36 & 1,2-Epoxydiphenyl ethane & 52 \\
\hline
\end{tabular}

${ }^{a}$ Olefin to resin ratio, $1: 2$; solvent, dioxan; temperature, $70^{\circ} \mathrm{C}$; ${ }^{\text {bincludes preswelling time; }}$ ${ }^{c}$ characterized by comparison with authentic samples (m.p./b.p. and IR); ${ }^{\mathrm{d}}$ temperature, $30^{\circ} \mathrm{C}$

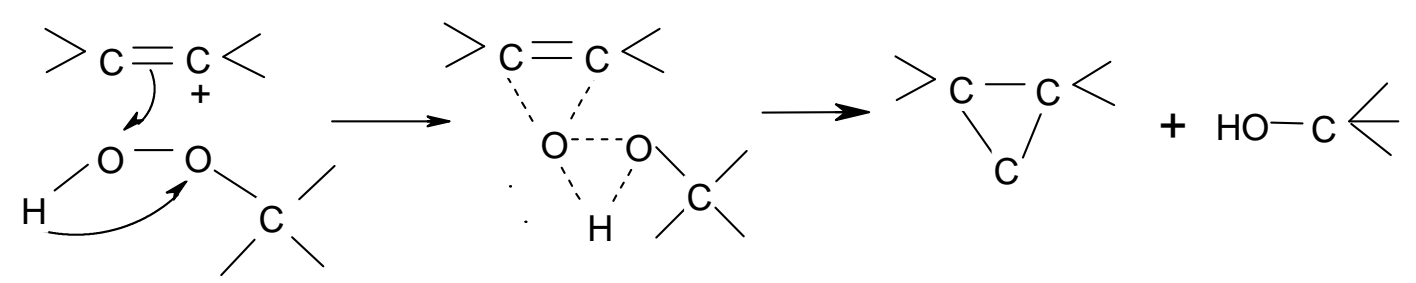

Scheme 2. Epoxidation of olefins using polymeric $t$-butyl hydroperoxide reagent.

The uncatalysed epoxidation yielded epoxides ranging from 40 to $58 \%$. When compared to the reaction with the DVB crosslinked system, this reagent showed more efficiency by reducing the reaction time considerably, even though an appreciable change was not observed in the yield of epoxide isolated. This was evidenced by the epoxidation of cyclohexene which required only $16 \mathrm{~h}$ instead of $24 \mathrm{~h}$ with the DVB crosslinked reagent. ${ }^{17}$ The reaction time for styrene was reduced from 56 to $48 \mathrm{~h}$, and that of ethyl cinnamate from 36 to $23 \mathrm{~h}$. The reaction temperature of the reaction varied with the nature of the olefins. In the case of vinyl monomers, epoxidation at higher temperature yielded polymerised products instead of the epoxides. Hence, the epoxidation of substrates like methyl methacrylate was conducted at room temperature. Substrates like cinnamic acid and ethyl cinnamate were epoxidised when the temperature was raised to $70^{\circ} \mathrm{C}$. The successful epoxidation of diphenyl acetylene in $52 \%$ yield after $36 \mathrm{~h}$ reveals the capability of the reagent to expoxidise acetylenic compounds. While cyclohexene epoxidised in $16 \mathrm{~h}$, acenaphthylene required $36 \mathrm{~h}$ for the reaction. Hence, the reaction seems to be diffusioncontrolled and depended on the molecular size of the substrate. The products were identified in comparison with the physical constants of authentic samples and from IR spectral values.

The epoxidation reactions were found to be accelerated to a great extent by the presence of catalysts such as benzyl triethyl ammonium hydroxide (BTEAH), molybdenum trioxide $\left(\mathrm{MoO}_{3}\right)$ and vanadium (V) oxyacetyl acetonate [VO (acac $\left.)_{2}\right]$. The details of the catalysed epoxidation reactions are shown in table 2. The effect of catalyst was examined for the epoxidation of cinnamic acid as well as cyclohexene. [VO $(\mathrm{acac})_{2}$ ] was found to be the most efficient catalyst among the three. The yield of epoxide was low with BTEAH. However the yield can be improved by increasing the reaction time. BTEAH being readily soluble in water, requires much simpler steps in the workup procedure when compared to [VO (acac $)_{2}$ ]. Hence the use of BTEAH which is a phase transfer catalyst seems to suit the reaction, particularly with solid-phase reagents.

The polymeric byproduct was identified to be polymeric $t$-butyl alcohol resin with structure (3). The polymeric alcohol obtained in each epoxidation reaction was washed with several solvents and recycled in a single step to polymeric $t$-butyl hydroper- 
Table 2. Catalysed epoxidation of olefins.

\begin{tabular}{lccccc}
\hline & \multicolumn{2}{c}{ Reaction time $(\mathrm{h})$ for } & & \multicolumn{2}{c}{ Isolated yield $^{\mathrm{c}}(\%)$ for } \\
\cline { 2 - 3 } \cline { 5 - 6 } Catalyst & Substrate $1^{\mathrm{a}}$ & Substrate $2^{\mathrm{b}}$ & & Substrate $1^{\mathrm{a}}$ & Substrate $2^{\mathrm{b}}$ \\
\hline BTEAH & 16 & 12 & & 90 & 84 \\
$\mathrm{MoO}_{3}$ & 14 & 14 & & 82 & 84 \\
$\mathrm{VO}(\mathrm{acac})_{2}$ & 12 & 10 & & 86 & 89 \\
\hline
\end{tabular}

${ }^{\mathrm{a}}$ Cinnamic acid; ${ }^{\mathrm{b}}$ cyclohexene; ${ }^{\mathrm{c}}$ substrate to resin $1: 2$; solvent, dioxan, temperature, $70^{\circ} \mathrm{C}$

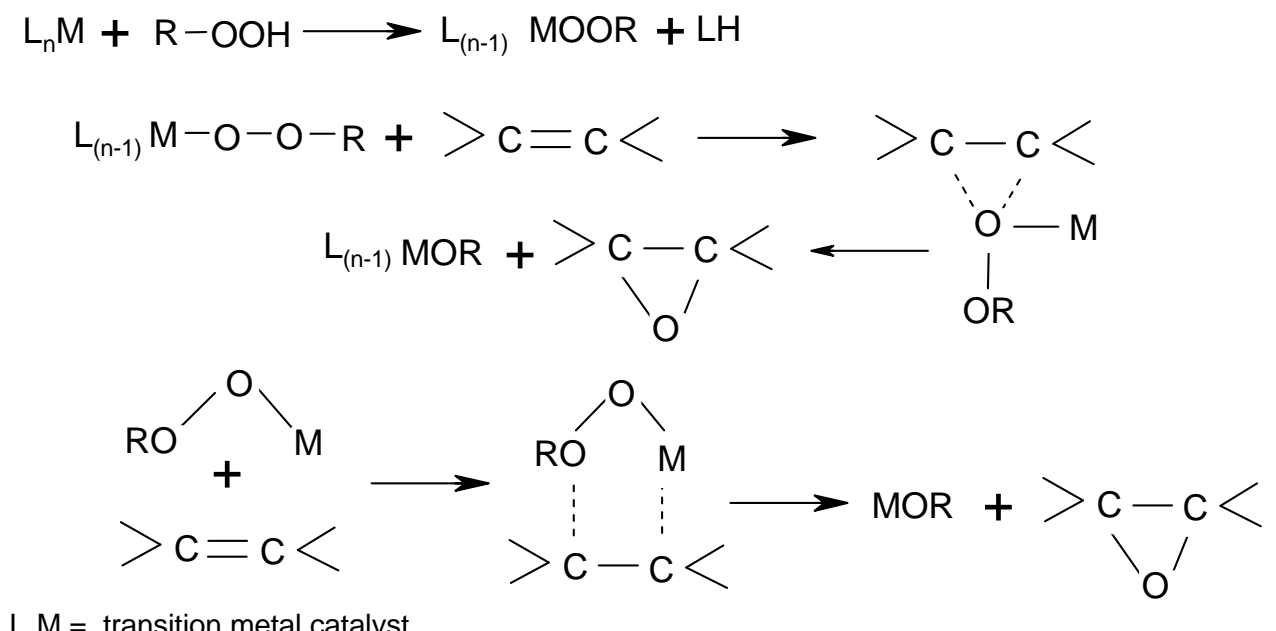

$L_{n} M=$ transition metal catalyst

Scheme 3. Probable mechanism for epoxidation of olefins.

oxide. Residual hydroperoxide capacity of the reagent was not affected considerably even after five cycles. Efficiency of the reagent remained more or less constant in terms of both yield and reaction time for the model epoxidation of cinnamic acid.

The reaction is assumed to follow first-order kinetics with respect to olefin and first order with respect to hydroperoxide, the overall reaction being a second-order process. Since large excess of the $t$-butyl hydroperoxide reagent was used it is assumed to follow pseudo first-order kinetics. The reaction is assumed to involve the nucleophilic attack of the olefin on the hydroperoxide followed by proton transfer probably by a concerted intramolecular process. The intermediate formed then decays to give the epoxide. The probable mechanism is depicted in scheme 3 . The presence of electron-releasing groups on the olefin increased the rate of epoxidation, cis double bonds were attacked faster than trans double bonds.

\subsection{Oxidation reactions}

The polymeric $t$-butyl hydroperoxide resin (4) was employed to perform the oxidation of alcohols both primary and secondary to aldehydes and ketones respectively in yields ranging from 54 to $85 \%$. The alcohols used, the products isolated and reaction conditions are presented in table 3 . The oxidation of alcohols by polymeric $t$-butyl hydroperoxide and its regeneration from the polymeric byproduct are shown in scheme 4 . The course of the oxidation reaction was monitored by tlc. The 1,4-BDDMA crosslinked polymer support to which the t-butyl hydroperoxide functionality was attached exerted a marked improvement on oxidation rate when compared to the DVB crosslinked one. ${ }^{17}$ Benzoin was oxidized to benzil in $85 \%$ yield within a period of $26 \mathrm{~h}$ while DVB crosslinked reagent produced only $82 \%$ benzil even after $36 \mathrm{~h}$. Benzhydrol was also found to show a more or less similar extent of reaction as benzoin. However, cholesterol was oxidised only in $43 \mathrm{~h}$. All substrates except cholesterol produced a singe product on oxidation. When cholesterol was oxidized a small amount of epoxide was also obtained along with cholestenone as in the case of the DVB crosslinked polystyrene supported $t$-butyl hydroperoxide. ${ }^{17}$ The reaction time was however reduced by about $14 \mathrm{~h}$, when compared to the previous 


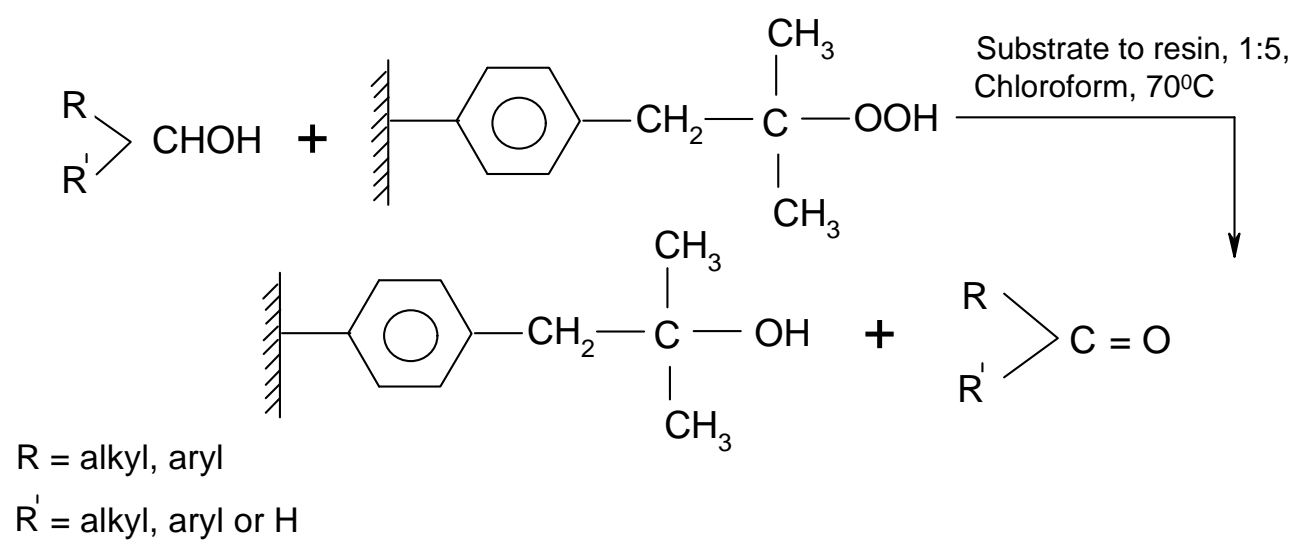

Scheme 4. Oxidation of alcohols using polymeric $t$-butyl hydroperoxide reagent.

Table 3. Oxidation of alcohols using 1,4-BDDMA crosslinked polystyrene-supported $t$-butyl hydroperoxide resin.

\begin{tabular}{lclc}
\hline Substrate $^{\mathrm{a}}$ & Reaction time $^{\mathrm{b}}(\mathrm{h})$ & \multicolumn{1}{c}{ Product $^{\mathrm{c}}$} & Isolated yield $(\%)^{\circ}$ \\
\hline Benzoin & 26 & Benzil & 85 \\
Cholesterol & 43 & Cholestenone and epoxide & 76 and 18 \\
Benzhydrol & 28 & Benzophenone & 82 \\
Benzyl alcohol & 20 & Benzaldehyde & 84 \\
$\alpha$-Phenyl ethanol & 24 & Acetophenone & 76 \\
$p$-Nitro- $\alpha$-phenyl ethanol & 24 & $p$-Nitroacetophenone & 54 \\
p-Chloro- $\alpha$-phenyl ethanol & 24 & $p$-Chloroacetophenone & 83 \\
$p$-Methyl- $\alpha$-phenyl ethanol & 24 & $p$-Methyl acetophenone & 60 \\
$p$-Methoxy- $\alpha$-phenyl ethanol & 24 & $p$-Methoxy acetophenone & 66 \\
\hline
\end{tabular}

${ }^{a}$ Alcohol to resin ratio $1: 5$, solvent, chloroform; temperature, $45^{\circ} \mathrm{C}$; ${ }^{b}$ includes preswelling time; ${ }^{\mathrm{c}}$ characterized by comparison with authentic samples (m.p./b.p. and IR)

system. The oxidizing efficiency of 1,4-BDDMA crosslinked polystyrene bound $t$-butyl hydroperoxide has been found to excel that of the DVB crosslinked reagent with respect to all the substrates investigated. This may be attributed to the polar and flexible nature of the crosslinker, 1,4-BDDMA, when compared to the non polar and rigid DVB; the former brings about a better hydrophilic-hydrophobic balance to the macromolecular environment.

The reaction rate was influenced by the molecular size of the substrate. Hence the reaction seemed to be diffusion-controlled. Cholesterol was epoxidised in $43 \mathrm{~h}$ while benzoin required only $26 \mathrm{~h}$. In addition, the nature of substituents present in the substrate influenced the reaction. Various substituted $\alpha$-phenyl ethanols were oxidized using the polymeric reagent. The presence of electron-withdrawing substituents favoured the oxidation reaction.

The catalysts tried previously for epoxidation were used in the oxidation reaction also. Details of catalysed oxidation of benzoin and benzhydrol with 1,4-BDDMA crosslinked polystyrene bound $t$-butyl hydroperoxide are presented in table 4 . The presence of catalysts reduced the reaction time considerably in both the cases studied [VO (acac $)_{2}$ ] has been found to be the most effective catalyst, among the three, with respect to reaction time and product yield. Product isolation was easy when BTEAH was used as the catalyst. The reaction rates were found to increase remarkably when compared to the uncatalysed reaction with all the three catalysts.

\section{Conclusion}

1,4-BDDMA crosslinked polystyrene-supported $t$ butyl hydroperoxide proved to be a better solid-phase organic reagent when compared to the DVB crosslinked reagent. It successfully performed the epoxidation of olefinic compounds. It was also efficient in oxidizing a number of alcohols. The presence of 
Table 4. Catalysed oxidation using 1,4-BDDMA crosslinked polystyrene-bound $t$-butyl hydroperoxide resin.

\begin{tabular}{lccccc}
\hline & \multicolumn{2}{c}{ Reaction time $^{\mathrm{c}}$ for } & & \multicolumn{2}{c}{ Product yield $^{\mathrm{c}}$} \\
\cline { 2 - 3 } \cline { 5 - 6 } Catalyst & Substrate $^{\mathrm{a}}$ & Substrate $2^{\mathrm{b}}$ & & Substrate $1^{\mathrm{a}}$ & ${\text { Substrate } 2^{\mathrm{b}}}^{\mathrm{S}}$ \\
\hline BTEAH & 14 & 12 & & 82 & 85 \\
$\mathrm{MoO}_{3}$ & 20 & 16 & & 85 & 86 \\
$\mathrm{VO}(\mathrm{acac})_{2}$ & 14 & 18 & & 88 & 86 \\
\hline
\end{tabular}

${ }^{\mathrm{a}}$ Benzoin; ${ }^{\mathrm{b}}$ benzhydrol; ${ }^{\mathrm{c}}$ substrate to resin ratio, $1: 5$; solvent, chloroform; temperature, $45^{\circ} \mathrm{C}$

catalysts like BTEAH. $\mathrm{MoO}_{3}$ and [VO (acac) $)_{2}$ accelerated the epoxidation and oxidation reactions to a great extent. Dioxan was found to be the most suitable solvent for epoxidation while acetonitrile proved best for oxidation. Both the reactions studied were temperature dependent. A five-fold molar excess of the reagent showed maximum efficiency with regard to both epoxidation and oxidation reactions.

\section{Acknowledgement}

The authors thank the Council of Scientific and Industrial Research, New Delhi for the award of a fellowship to MSS.

\section{References}

1. Sakahara S, Yajima K, Belosludev R, Takami S, Kubo M and Miyamota A 2002 Appl. Surf. Sci. 189253

2. Zhansu B M 2002 Curr. Opin. Chem. Biol. 6347

3. Boyle N A and Janda K D 2002 Curr. Opin. Chem. Biol. 6339
4. Itozumi Y and Nakai Y 2002 Org. Lett. 42997

5. Zhu S, Shi S, Gerritz S W and Sofia M J 2003 J. Combinat. Chem. 5205

6. Guo H, Shi X, Qiao Z, Hou S and Wang M 2002 Chem. Commun. 118

7. Uozumi Y and Nakai Y 2002 Org. Lett. 42997

8. Brown D S, Kerr W J, Lindsay D M, Pike K G and Ratcliffe P D 2001 SynLett 1257

9. Sasidharan M, We P and Tatsumi T 2002 J. Catal. 205332

10. Matsuo J, Kawana A, Pudhom K and Mukaiyama T 2002 Chem. Lett. 250

11. Sheela M S and Sreekumar K 2003 J. Polym. Sci. Chem. (communicated)

12. Sreekumar K and Pillai V N R 1989 Macromolecules 223303

13. George B K and Pillai V N R 1990 Proc. Indian Acad. Sci. (Chem. Sci.) 102521

14. Akelah A and Moet A 1990 Functionalized polymers and their applications (London: Chapman and Hall)

15. Sreekumar K and Pillai V N R 1987 Polymer 28 1599

16. Sheela M S and Sreekumar K 2003 Polym. Int. (communicated)

17. Sheela M S and Sreekumar K 2004 Indian J. Chem. (communicated) 